\section{Cureus}

Received 01/08/2013

Review began 01/09/2013

Published 02/27/2013

\section{(c) Copyright 2013}

Landy et al. This is an open access article distributed under the terms of the Creative Commons Attribution License CC-BY 3.0., which permits unrestricted use, distribution, and reproduction in any medium, provided the original author and source are credited.

\title{
The Use of Facebook Among Seventy-Seven Departments of Anesthesia in United States Medical Schools
}

\author{
J.S. Landy ${ }^{1}$, Alex Macario ${ }^{2}$ \\ 1. Internal Medicine and Critical Care Toronto, Canada; Visiting Scholar, Stanford University 2. \\ Anesthesiology, Perioperative and Pain Medicine, Stanford University School of Medicine, Stanford, USA
}

$\square$ Corresponding author: J.S. Landy, joshualandy.md@gmail.com

Disclosures can be found in Additional Information at the end of the article

\section{Abstract}

Background: Online social networks permit users to contribute and share information with greater ease and convenience than ever before. Companies of all sizes are choosing to connect with their employees, customers, and audience with online social networks.

Objective: The goals of this study were to measure the percentage of Departments of Anesthesia in U.S. Medical Schools that have a Facebook page, and to quantify the content and activity on those sites. This data will be used to create a profile of the current use of common social media among departments of Anesthesia in 2012.

Methods: Seventy-seven academic anesthesia departments were chosen as listed on U.S. News' Best Research Medical Schools. Facebook was searched for pages bearing the identification of the university and anesthesia department. Pages were categorized as: 1) Profile, 2) Open Group, 3) Closed Group, or 4) Community. Content was assessed including number of posts in the previous 30 days, photographs, and friends/members, as well as presence of unprofessional content.

Results: Twenty-seven of the 77 anesthesia departments (35\%) have Facebook pages, with eight having two separate pages for a total of 35 pages. Fifteen of these were established intentionally by the department in either the Profile or Group format. Nineteen of the remaining twenty pages were established by Facebook itself as Community pages to identify a workplace. Three (9\%) department pages contained photos of users or group members. No departments posted photographs of patients. No unprofessional content was found on any page. Thirty-one (89\%) of the 35 Facebook pages had no activity (posting news, comments, or media) within the past 30 days. Twenty (57\%) pages had no users, followers, friends, or "likes", and 18 (51\%) pages had no content. The median number of friends or members was 0 (mean 34 (SD +/- 95.9), maximum 501). Information on social events was found on five pages (14\%), department fundraising (1 page, $3 \%$ ), news or faculty updates (two pages, $6 \%$ ), job postings (three pages, 9\%), links to the residency website (four pages, 11\%), and alumni updates (one page, 3\%). Websites with Closed Groups (three pages, 9\%) were not accessible to evaluate their contents.

Conclusions: Although social networks can be a rich medium to reach a general audience, only approximately one-third of anesthesia departments in the U.S. have Facebook pages, which generally have minimal activity and content. This medium has undeveloped potential to reach colleagues, alumni, trainees, and recruits. 
Categories: Anesthesiology, Medical Education, Miscellaneous

Keywords: personnel selection, social media, anesthesiology, internship and residency, communication, recruitment

\section{Introduction}

Online social networks have transformed the way people interact, especially among the Millennial generation, by permitting users to contribute and share information with greater ease and convenience than ever before [1-3]. Companies of all sizes are choosing to connect with their employees, customers, and audience with online social networks, like Facebook, Twitter, and LinkedIn [4]. These and other media platforms are also becoming more common in healthcare. This is in part due to the ubiquity of smartphones among physicians and medical students [5]. As of May 2012, Facebook had over 900 million active users, more than half of them using Facebook on a mobile device [6].

Facebook may be helpful for a variety of uses, including recruiting patients for studies [7], providing community support groups for providers and patients [8], and fundraising and raising awareness for specific conditions [9]. Social network sites may also be an effective strategy for the health education of medical students [10] as well as resident education [11], especially since 85\% of residents in ACGME programs have smartphones [12]. Facebook accounts are common among health science students (64-96\%) and 13-47\% of health care providers have an account [13]. However, professionalism breaches related to social network sites occur. For example, 11\% of applicants to an otolaryngology residency had Facebook profiles with pictures or text deemed as unprofessional [14].

Academic departments in medical schools could use social networking sites for a variety of purposes, including updating readers on department activities such as: newly published manuscripts or grants obtained, disseminating a newsletter with resident accomplishments, announcing new faculty hires or departures, educating patients, recruiting subjects for research studies, fundraising, job networking for residents, and/or other alumni affairs, for example, notification of upcoming reunions. Doximity and LinkedIn are social networking websites that focus on professionals and could be used for such purposes. One important difference between Facebook and LinkedIn is that only the named user is able to modify the content of a LinkedIn profile webpage. Although many social networking sites exist, Facebook is the most frequently used.

The goals of this study were to measure the percentage of Departments of Anesthesia in U.S. Medical School that have a Facebook page, and to quantify the content and activity on those pages. This information may be useful to Anesthesia Departments interested in leveraging social media to build strong connections, recruit and disseminate information.

\section{Materials And Methods}

The Stanford IRB, noting that no human subjects were involved, approved this study.

The top seventy-five universities were chosen as listed on U.S. News' Best Research Medical Schools [15]. On August 1, 2012, JSL conducted a search of Facebook using the university's name and the terms "anesthesia" and "anesthesiology."

Any pages bearing the title of the university and the name of the anesthesia department or anesthesia were studied. A second investigator independently confirmed the extracted information.

Administrative groups, such as companies or departments, can be present on Facebook in 
several formats. The sites found were categorized into one of the following:

1) Profile: This is the format common to most users. This page may contain personalized demographic information about the user, links to photos, a list of friends, and a newsfeed, which can be updated by the user and includes updates from the user's friends.

2) Open group: An organization can launch a group page to provide its associates with content which may be updated, photographs, and short news items known as posts. This page is similar to a profile but does not contain an individual's demographic information. Group pages can be established by any Facebook user, and groups can be open or closed. Open groups permit any interested party to view the contents of the group page and join the group.

3) Closed group: This type of group allows access only to members permitted by an administrator.

4) Community: This Facebook format type is created automatically by Facebook administrators if multiple users indicate that they interact with a location or program (e.g., a workplace). Community pages, once generated, can host comments, photographs, and other content placed by linked users. If a workplace has a preexisting group page, and a user does not link his or her workplace to the preexisting group, a community page will automatically be rendered. Different spellings or manifestations of workplace names may result in multiple community pages. These represent the same workplace and for purposes of this study were treated as such.

A data collection form was created to measure content on each Facebook site including: number of photographs, number of friends/members, presence of unprofessional content (e.g., HIPPA violations, alcohol consumption, profanity in status updates), and number of posts in previous 30 days. Only information available in the public domain, not requiring permission from the profile owner, was assessed.

\section{Results}

Seventy-four (99\%) of the 75 medical schools listed in U.S. News Best Research Medical Schools have anesthesia departments. Brown University does not have a separate Department of Anesthesiology. Three Harvard-affiliated anesthesia residencies were included for a total of 77 academic anesthesia departments studied.

Twenty-seven (36\%) of the 77 anesthesia departments have Facebook pages (Table 1). Eight anesthesia departments (11\%) have two Facebook pages for a total of 35 separate pages.

Of the 35 Facebook pages, fifteen have pages established intentionally by the department in either the profile or group format. The remaining twenty pages were either established by Facebook itself as community pages to identify a workplace (19 pages, $54 \%$ ), or one group page was established by a student interest group (Figure 1). 


\section{Cureus}

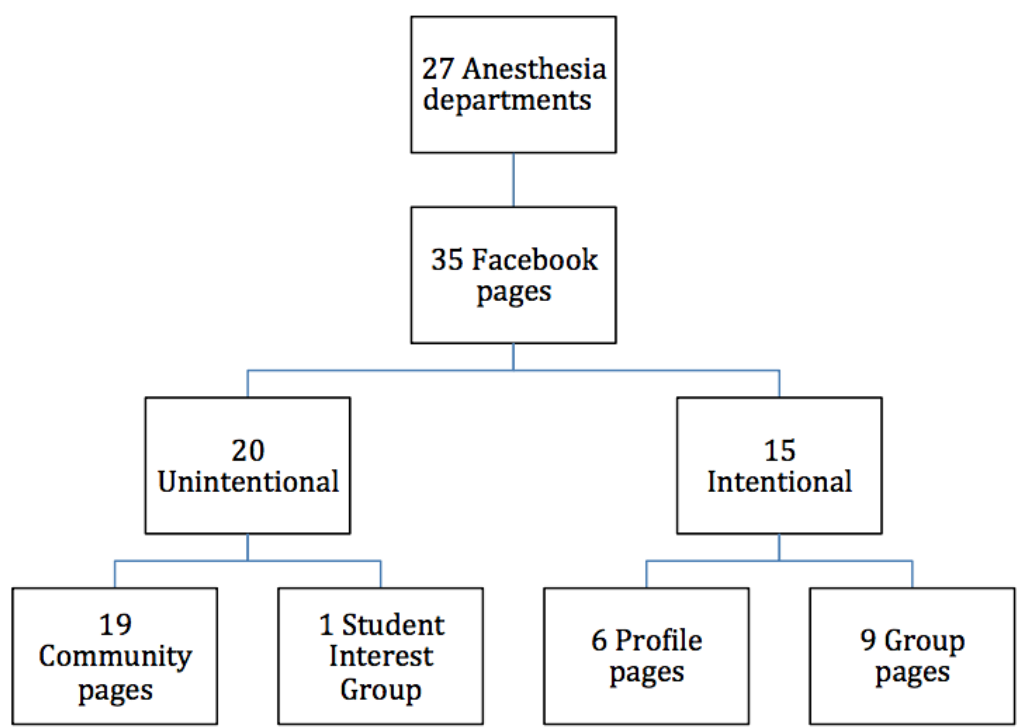

\section{FIGURE 1: Distribution of Facebook page types.}

Of the 27 anesthesia departments, 15 have pages established intentionally by the department in either the Profile or Group format. The remaining 20 pages were established by Facebook itself as Community pages to identify a workplace, or by students.

Sixteen of the 27 (47\%) department Facebook pages had posted photographs, either generic anesthesia images or the logo of the university. Three (9\%) department pages contained photos of users or group members. No departments posted photographs of patients. No unprofessional content was found on any site.

Websites with closed groups (three pages, 9\%) were not accessible. Thus, their contents could not be evaluated.

Thirty-one (89\%) of the 35 Facebook pages had no activity (posting news, comments, or media) within the past 30 days. Twenty (57\%) pages had no users, followers, friends, or "likes", and 18 (51\%) pages had no content. Twenty-three of 27 Facebook pages had no posts in the previous 30 days. The median number of friend or members was 0 (mean 34 (SD +/- 95.9), maximum 501).

Five pages (14\%) contained information on social events, four pages (12\%) contained links to the residency website, one page (3\%) contain information about department fundraising, two pages (6\%) posted department news or faculty updates, three pages contained job postings (9\%), and one page contained alumni updates (3\%). No pages $(0 \%)$ included information on applying to the residency program.

\section{Anesthesia Department}

Baylor College of Medicine

Boston University

Case Western Reserve University

Columbia University

\section{Facebook Page}

Linkedln Page

No

No

No No

No No

Yes No 


\section{Cureus}

Cornell University

Dartmouth Medical School

Duke University

Emory University

George Washington University

Georgetown University

Georgia Health Sciences University

Harvard University (Beth Deaconess Medical Center)

Harvard University (Brigham and Women's Hospital)

Harvard University (Massachusetts General Hospital)

Indiana University - Indianapolis

Jefferson Medical College

Johns Hopkins University

Mayo Medical School

Medical College of Wisconsin

Medical University of South Carolina

Mount Sinai School of Medicine

New York University

Northwestern

Ohio State University

Oregon Health and Science University

Rush University

St. Louis University

Stanford University

Stony Brook University--SUNY

Temple University

Tufts

Uniformed Services University of the Health Sciences (Hebert)

University at Buffalo--SUNY

University of Alabama - Birmingham

University of California - Irvine
No

No

Yes

No

Yes

No

Yes

No

No

No

No

No

No

No

No

No

No

No

Yes

No

Yes

No

No

No

Yes

No

No

No

Yes

No

No

No

No

No

Yes

No

Yes

No

Yes

No

No

No

No

No

No

No

No

No

No

No

No

No

No

No

No

No

No

No

No

No

Yes

No 


\section{Cureus}

University of California-Davis

University of California_Los Angeles

Yes

No

University of California-San Diego

No

University of California-San Francisco

No

No

University of Chicago

No

University of Cincinnati

No

University of Colorado

No

University of Connecticut

No

University of Florida

Yes

University of Illinois

No

University of lowa

No

University of Kansas Medical Center

No

University of Kentucky

No

University of Louisville

No

University of Maryland

No

University of Miami

No

University of Miami (Miller)

No

University of Michigan--Ann Arbor

Yes

No

University of Minnesota

No

No

University of Missouri

No

No

University of Nebraska Medical Center

Yes

No

University of North Carolina Chapel Hill

No

No

University of Oklahoma

Yes

No

University of Pennsylvania

Yes

No

University of Pittsburgh

No

No

University of Rochester

Yes

No

University of Southern California (Keck)

No

No

University of Texas Health Science Center--Houston

No

No

University of Texas Health Science Center--San Antonio

No

No

University of Texas Southwestern Medical Center--Dallas

No

No

University of Utah

Yes

No 


\section{Cureus}

University of Vermont

No

University of Virginia

University of Washington

University of Wisconsin - Madison

Vanderbilt University

Virginia Commonwealth University

Wake Forest University

Washington University in St. Louis

Yale University

$\begin{array}{ll}\text { No } & \text { Yes } \\ \text { Yes } & \text { No } \\ \text { Yes } & \text { Yes } \\ \text { Yes } & \text { No } \\ \text { No } & \text { No } \\ \text { No } & \text { No } \\ \text { Yes } & \text { Yes } \\ \text { No } & \text { No }\end{array}$

TABLE 1: Online social networking sites for university affiliated anesthesia departments

\section{Discussion}

While every anesthesia department studied had its own department website, the principal finding of this study is that $36 \%$ of the 77 university affiliated departments have a Facebook page. Of these, approximately half were established intentionally by the department in either the profile or group format. The pages not established by departments were either group pages established by trainees with the purpose of socializing and communicating among their cohort, or by Facebook itself as community pages, to identify a workplace.

Overall activity on the anesthesia department Facebook pages that did exist was low. Our quantitative content analysis showed that 23 of 27 Facebook pages had no posts in the previous 30 days and the median number of friends/members equaled 0 . Nineteen of these 23 pages, representing 54\% of all department Facebook pages were in the community format and were therefore not established by the University intentionally. It would be unfair to describe these pages as under-utilized since the department may not be aware of the page's existence.

Low participation rates may be a bit surprising because online social networks, like Facebook, make it easier for people and groups to stay connected. For example, users are able to show their list of friends, which may result in connections between individuals that would not otherwise have met. Facebook may also help users maintain relationships after they change communities, such as when housestaff graduate and leave the institution. Facebook also should be attractive for those that want to maintain a large, diffuse network of professional relationships for an entire career.

We found three Facebook pages established by current anesthesia trainees and one page by a student interest group for potential applicants. The presence of these Facebook pages not administered by the department suggests some appetite may be present for this type of presence on the Internet. Given the interest and use of Facebook and other smartphoneenabled social networking websites among medical trainees and physicians, it is likely that more academic anesthesia departments will increasingly choose to connect with users on Facebook and other social networking sites. 
Several explanations may exist for the low prevalence and activity of Facebook pages among academic anesthesia departments in the U.S. These include: 1 ) the need to identify and fund a person in the department to establish and maintain a Facebook page; 2) the lack of clear accountability or "owner" for a Facebook page (residency director, chief resident, business office, or other) within a department; 3) unclear mission statement or benefits or goals of establishing a Facebook page; 4) the desire by physicians or administrators not to mix their professional life with their personal life; 5 ) the potentially cumbersome process of seeking departmental approval for posting content which could risk having a page but with no activity thereby being an overall negative for the department; 6) the presence of an online network local to the university or department; and 7) departments are using one of the other social media outlets instead of Facebook.

Professional organizations recommend cautious use of these networks to their employees and representatives [16]. Many codify their concerns in the form of policy, including the American Medical Association (AMA) [17]. Permitting unprofessional content to reach one's workplace can be damaging to patient care and to the workplace. Although having appropriate privacy settings can avoid this, restricting interaction may simultaneously stifle interprofessional connections. In a recent nationwide survey of medical students, residents, and practicing physicians, $9 \%$ of respondents had been contacted by a patient over a social network [18]. A majority of the respondents expressed concerns about doctor-patient confidentiality, indicating that physicians and patients interacting on a social network is not ethically acceptable.

Potential future uses of social networking sites that add value by enhancing communication or augmenting the brand for anesthesia departments is a topic that deserves further study. This includes innovative ways to interact and engage with the public. Although anesthesia departments have websites, many lack information (such as resident work schedules or information regarding career or fellowship opportunities following residency) sought for by residency applicants [19]. Among university websites, only $46 \%$ were judged to be adequate by medical students applying for residency [20]. In contrast, the data collected in this study indicate that academic anesthesia departments are not using Facebook as a strategy to market their programs to potential applicants or to engage alumni.

The use of social networks to connect with residency programs can be bidirectional. Some residency programs have used Facebook to view the profiles of prospective candidates. In a 2011 survey, 17\% of surgery program directors reported they had searched social networks to learn more about a candidate's extracurricular activity, including unprofessional behavior [21]. From the results of our study, it seems likely that survey of an applicant's social activity likely originates from the personal account of an individual and not an official department associated account.

This study has several limitations. Not all Facebook information was available for all groups. In closed groups, there may be more content and richer activity than what we were able to access. Additionally, If a department did not use the full name of the university, then our search strategies may have been inadequate to locate their Facebook. Also, other social networking sites may be available for academic departments to use. For example, although four of the 77 anesthesia departments have LinkedIn websites, information on LinkedIn is restricted to members who possess associations to each institution and thus is not available for assessment. Another platform, Twitter, was not included in this study due to its lack of category specific search capability.

\section{Conclusions}

Anesthesia departments should be leveraging social media to build strong connections, recruit 


\section{Cureus}

and disseminate information. The main objective of this study was to identify the content available on Facebook pages of academic anesthesia departments. Patients or other medical professionals or prospective residency applicants interested in a particular department might undertake this type of search. The results indicate that even though social networks can be a rich medium to reach a general audience, at the moment, U.S. Departments of Anesthesia are not using this tool to its full potential. Activity and content was generally low. An initial simple remedy, for example, may be to post information that currently exists on department websites which could also be included on Facebook pages.

\begin{tabular}{|c|c|c|c|c|}
\hline Anesthesia Department & Page Type & Number of Photos & $\begin{array}{l}\text { Number of Friends } \\
\text { and Members }\end{array}$ & $\begin{array}{l}\text { Number of Posts in } \\
\text { Prior } 30 \text { Days }\end{array}$ \\
\hline Columbia University & Community & 0 & 0 & 0 \\
\hline Dartmouth Medical School & Community & 0 & 0 & 0 \\
\hline Duke University & Group & 191 & -1 & 7 \\
\hline Duke University & Profile & 113 & 501 & 0 \\
\hline Emory University & Class group & 0 & 22 & 0 \\
\hline Emory University & Closed group & 1 & 14 & 1 \\
\hline $\begin{array}{l}\text { Harvard University (Massachusetts } \\
\text { General Hospital) }\end{array}$ & Profile & 12 & 204 & 6 \\
\hline Indiana University - Indianapolis & Community & 0 & 0 & 0 \\
\hline Johns Hopkins University & Group & 2 & 0 & 0 \\
\hline Medical College of Wisconsin & Community & 0 & 0 & 0 \\
\hline New York University & Community & 0 & 0 & 0 \\
\hline Northwestern & Class Group & 0 & 17 & 0 \\
\hline Ohio State University & Community & 98 & 13 & 19 \\
\hline University of California - Irvine & Profile & 0 & 0 & 0 \\
\hline University of California - Irvine & Community & 0 & 0 & 0 \\
\hline $\begin{array}{l}\text { University of California-Los } \\
\text { Angeles }\end{array}$ & Class group & 2 & 20 & 1 \\
\hline $\begin{array}{l}\text { University of California-Los } \\
\text { Angeles }\end{array}$ & Community & 0 & 0 & 0 \\
\hline University of Colorado & $\begin{array}{l}\text { Student } \\
\text { interest group }\end{array}$ & 6 & 0 & 0 \\
\hline University of Kentucky & Community & 0 & 0 & 0 \\
\hline University of Miami & Profile & 2 & 199 & 0 \\
\hline University of Miami & Community & 1 & 0 & 0 \\
\hline
\end{tabular}




\section{Cureus}

$\begin{array}{lllll}\text { University of Miami (Miller) } & \text { Community } & 0 & 0 & 0 \\ \text { University of Michigan--Ann Arbor } & \text { Community } & 0 & 0 & 0 \\ \begin{array}{l}\text { University of Nebraska Medical } \\ \text { Center }\end{array} & \text { Community } & 0 & 0 & 0 \\ \text { University of Oklahoma } & \text { Community } & 0 & 0 & 0 \\ \text { University of Pennsylvania } & \text { Profile } & 5 & 1 & 0 \\ \text { University of Pennsylvania } & \text { Community } & 0 & 0 & 0\end{array}$

\section{TABLE 2: Facebook Page Format, Content and Activity}

\section{Additional Information \\ Disclosures}

Human subjects: All authors have confirmed that this study did not involve human participants or tissue. Animal subjects: All authors have confirmed that this study did not involve animal subjects or tissue. Conflicts of interest: In compliance with the ICMJE uniform disclosure form, all authors declare the following: Payment/services info: All authors have declared that no financial support was received from any organization for the submitted work. Financial relationships: All authors have declared that they have no financial relationships at present or within the previous three years with any organizations that might have an interest in the submitted work. Other relationships: All authors have declared that there are no other relationships or activities that could appear to have influenced the submitted work.

\section{References}

1. Chu LF, Zamora AK, Young CA, Kurup V, Macario A: The role of social networking applications in the medical academic environment. Int Anesthesiol Clin. 2010, 48:61-82. 10.1097/AIA.0b013e3181e6e7d8

2. Epstein B: HOW TO : Use Facebook for Professional Networking Setting up your Facebook for business networking. Mashable.com. 2009, Accessed: 2012 Jul 31: http://mashable.com/2009/08/14/facebook-networking/.

3. Modahl M, Tompsett L, and Moorhead T: Doctors, Patients \& Social Media. QuantiaMD. 2012, Accessed: 2012-08-01: http://www.quantiamd.com/q-qcp/doctorspatientsocialmedia.pdf.

4. Putzer GJ, Park Y: Are physicians likely to adopt emerging mobile technologies? Attitudes and innovation factors affecting smartphone use in the southeastern United States. Perspect Health Inf Manag. 2012, 9:1b. http://www.ncbi.nlm.nih.gov/pmc/articles/PMC3329206/.

5. Garven JJ: Social media: the word of mouth revolution. Northwest dentistry. 2010, 89:33-5, 68.

6. Sengupta S: Facebook's Prospects May Rest on Trove of Data . New York Times. Accessed: 2012-08-16: http:/www.nytimes.com/2012/05/15/technology/facebook-needs-to-turn-datatrove-into-investor-gold.html?pagewanted=2\&_r=1.

7. Nwadiuko J, Isbell P, Zolotor AJ, Hussey J, Kotch JB: Using social networking sites in subject tracing. Field Met. 2011, 23:77-85. 10.1177/1525822X10384088

8. Farmer AD, Bruckner Holt CE, Cook MJ, Hearing SD: Social networking sites: a novel portal for communication. Postgrad Med J. 2009, 85:455-459. 10.1136/pgmj .2008.074674

9. Bender J, Jimenez-Marroquin M, Jadad A: Seeking Support on Facebook: A Content Analysis of Breast Cancer Groups. J Med Internet Res. 2011, 13:e16. 
10. Mena G, Llupia A, Garcia-Basteiro AL, Aldea M, Sequera V-G, Trilla A: The willingness of medical students to use facebook as a training channel for professional habits: the case of influenza vaccination. Cyberpsychology, behavior and social networking. 2012, 15:328-31.

11. Chu LF, Zamora AK, Young CA: The Role of Social Networking Applications in the Medical Academic Environment. Int Anesthesiol Clin. 2010 , 48:61-82.

12. Franko OI, Tirrell TF: Smartphone App Use Among Medical Providers in ACGME Training Programs. J Med Syst. 2012, 36:3135-3139.

13. von Muhlen M, Ohno-Machado L: Reviewing social media use by clinicians . J Am Med Inform Assoc. 2012, 19:777-81.

14. Golden JB, Sweeny L, Bush B, Carroll WR: Social networking and professionalism in otolaryngology residency applicants. Laryngoscope. 2012, 122:1493-6.

15. Best Medical Schools: Research. US News. (2012). Accessed: 2012-08-08: http://gradschools.usnews.rankingsandreviews.com/best-graduate-schools/top-medicalschools/research-rankings.

16. Ginory A, Sabatier LM, Eth S: Addressing therapeutic boundaries in social networking . Psychiatry . 2012, 75:40-8.

17. American Medical Association. AMA Policy: Professionalism in the Use of Social Media . Accessed: 2012-08-11: http://www.ama-assn.org/ama/pub/meeting/professionalism-socialmedia_print.html.

18. Bosslet GT, Torke AM, Hickman SE, Terry CL, Helft PR: The patient-doctor relationship and online social networks: results of a national survey. Journal of general internal medicine. 2011, 26:1168-74.

19. Chu LF, Young CA, Zamora AK, Lowe D, Hoang DB, Pearl RG, Macario A: Self-reported information needs of anesthesia residency applicants and analysis of applicant-related web sites resources at 131 United States training programs. Anesthesia Analgesia. 2011, 112:430-9.

20. Embi PJ, Desai S, Cooney TG: Use and utility of Web-based residency program information: a survey of residency applicants. Journal of medical Internet research. 2003, 5:e22.

21. Go PH, Klaassen Z, Chamberlain RS: Attitudes and practices of surgery residency program directors toward the use of social networking profiles to select residency candidates: a nationwide survey analysis. Journal of surgical education. 2012, 69:292-300. 